SHORT REPORT

\title{
Atomoxetine-induced electrocardiogram changes
}

\section{A S Rajesh, G Bates, J G C Wright}

Arch Dis Child 2006;91:1023-1024. doi: 10.1136/adc.2005.087460

$\mathrm{T}$ his is a case report of an 11-year-old boy with attention deficit hyperactivity disorder who developed unusual cardiac repolarisation changes associated with palpitations on treatment with a standard dose of atomoxetine. The unusual cardiac repolarisation changes on the electrocardiogram (ECG) disappeared on stopping the atomoxetine. The importance of ECG monitoring for palpitations associated with atomoxetine and the need for long-term cardiovascular safety studies for atomoxetine in children and adolescents are highlighted.

Atomoxetine is a potent inhibitor of the presynaptic norepinephrine transporters, and is the first non-stimulant drug licensed for the treatment of attention-deficit hyperactivity disorder (ADHD).

Several noradrenergic drugs have been associated with adverse effects on the cardiovascular system, including abnormalities in heart rate, blood pressure or cardiac rhythm. However, in paediatric trials of atomoxetine, cardiovascular adverse events were rare and not significantly more common than in those receiving placebo. ${ }^{1}$ A significant difference between patients treated with atomoxetine and those treated with placebo was detected only for palpitation $(3.7 \% \vee 0.8 \%$; $\mathrm{p}=0.037)$ in the adult study population. ${ }^{1}$ At clinically relevant doses, atomoxetine has been shown to have no effect on cardiac repolarisation, as measured by the QTc interval, and has been recommended for safe use in children and adolescents. ${ }^{1}$

We describe a patient with atomoxetine-induced cardiac repolarisation changes associated with palpitations, which led to discontinuation of the drug.

The patient was a 11-year-old boy with a history of ADHD from the age of 5 years. He was of normal general intelligence and had no history of cardiac or other medical problems. His mother was a nurse. He initially showed a good response to stimulants, but on a modified release preparation suddenly developed severe tics. Concerta (longacting methylphenidate preparation) was stopped and his mother refused to allow him to go back on stimulants. He was treated with atomoxetine at a dose of $40 \mathrm{mg}(1.1 \mathrm{mg} / \mathrm{kg} /$ day). He showed a good response and continued taking the drug.

Ten months into treatment, he developed sensations of fluttering in his chest associated with pallor. No associated dizziness, nausea or vomiting was observed. The frequency of these episodes increased, and occurred around three times a week, lasting about 10 min each time. The symptoms were not associated with exertion and no other triggers were evident.

An echocardiogram showed normal ventricular function, with no evidence of cardiomyopathy or valvular abnormalities. His electrocardiogram (ECG) showed sinus rhythm, but there were unusual repolarisation changes after his $\mathrm{T}$ wave. Both his symptoms and the ECG abnormalities disappeared on stopping the drug (QTc when receiving atomoxetine $=0.32 \mathrm{~s}$, QTc when not receiving atomoxetine $=0.31 \mathrm{~s}$, figs 1 and 2).

We believe this to be the first published case of atomoxetine-induced unusual repolarisation changes. These were associated with palpitations and led to discontinuation of the drug. This experience highlights that although routine ECG testing is not mandatory in atomoxetine treatment, palpitations are unusual enough to warrant an ECG.
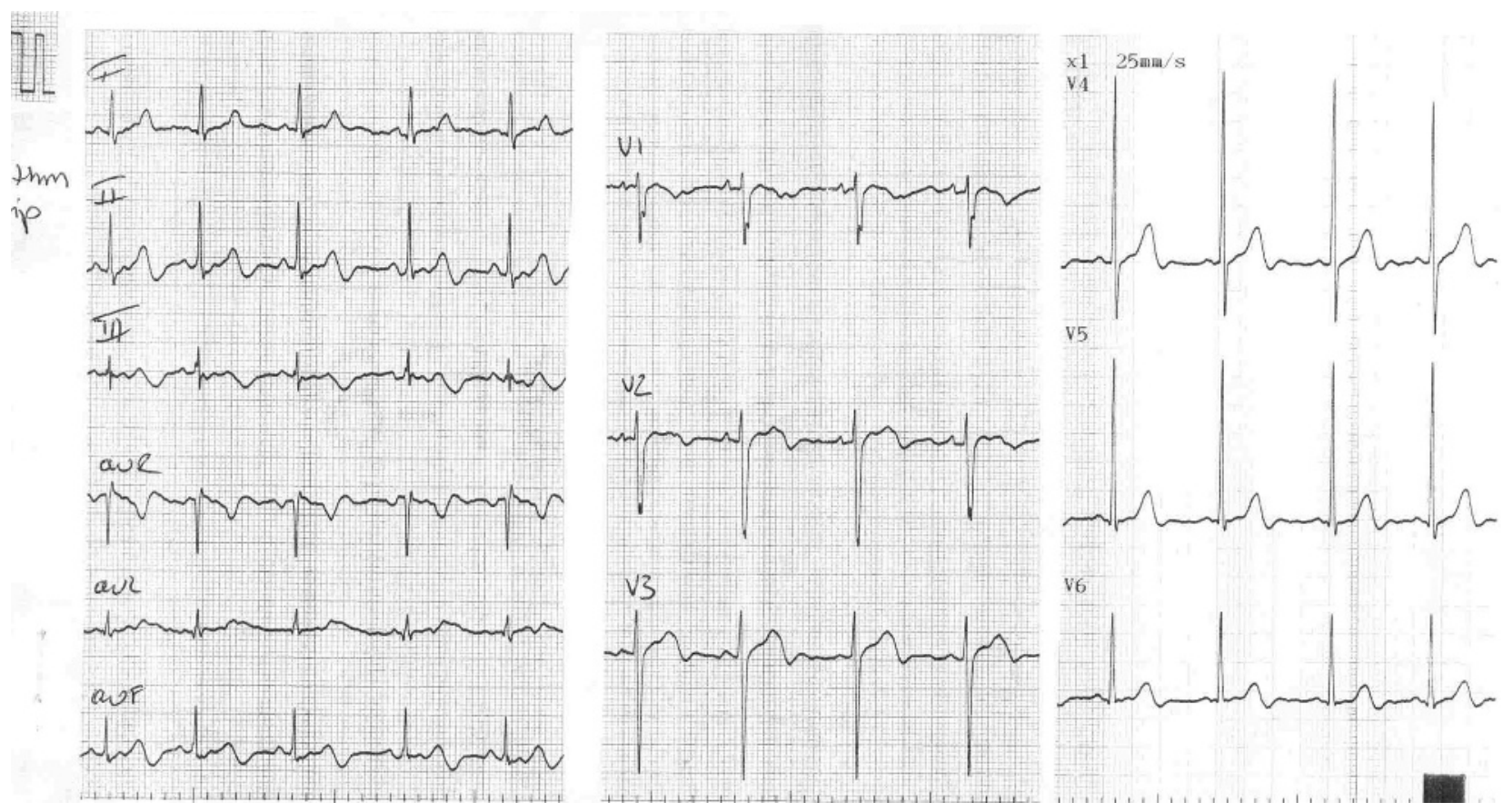

Figure 1 Electrocardiogram showing unusual repolarisation changes when receiving atomoxetine. 


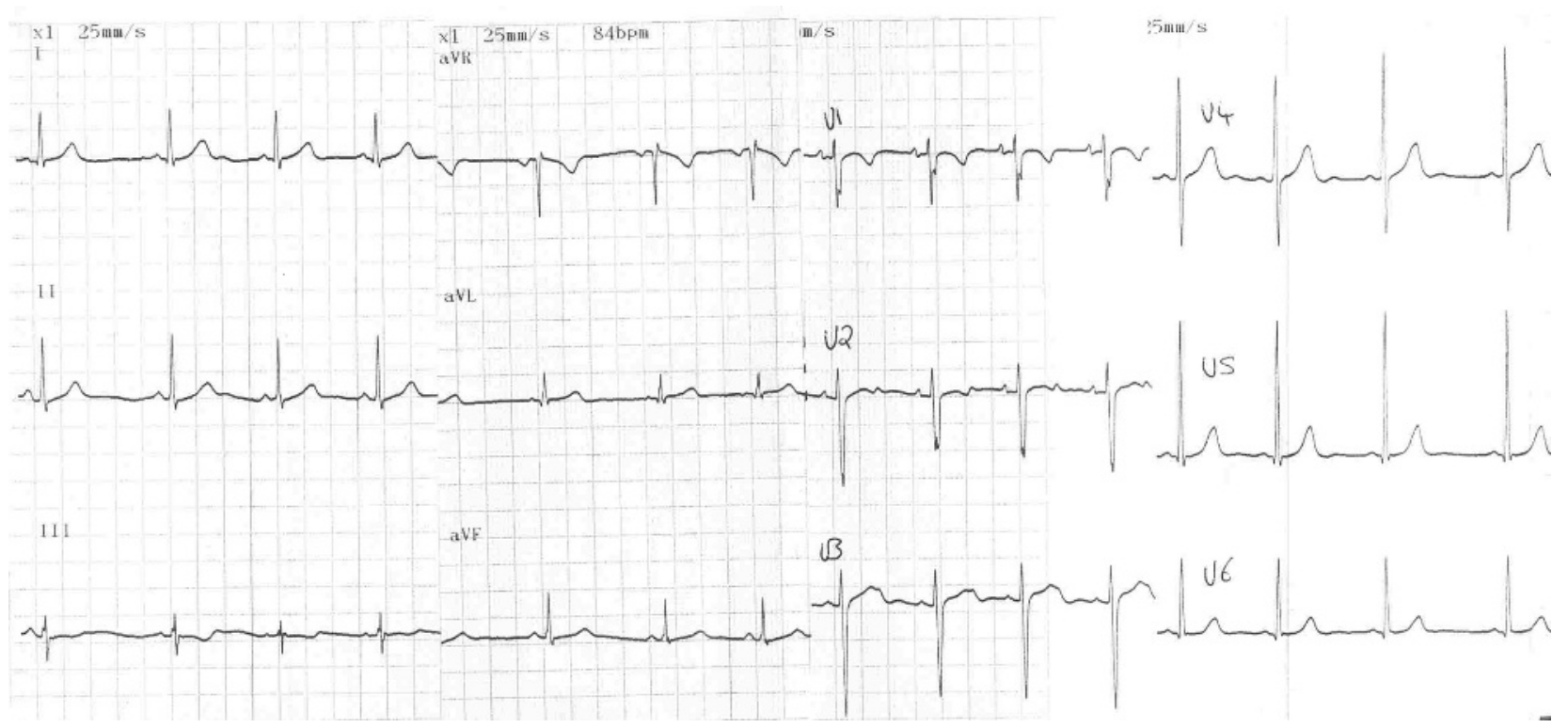

Figure 2 Normal electrocardiogram findings when atomoxetine was stopped.

Further research is needed to study the long-term effects of atomoxetine on the cardiovascular system in children and adolescents.

\section{Authors' affiliations}

A S Rajesh, G Bates, Parkview Clinic, Birmingham, UK J G C Wright, Birmingham Children's Hospital, Birmingham

Competing interests: None declared.
Correspondence to: A S Rajesh, Parkview Clinic, 60 Queensbridge Road, Moseley, Birmingham B 13 8QE, UK; arunarajesh1@hotmail.com Accepted 21 July 2006

\section{REFERENCE}

1 Wernicke JF, Faries D, Girod D, et al. Cardiovascular effects of atomoxetine in children, adolescents and adults. Drug Saf 2003;26:729-40. 